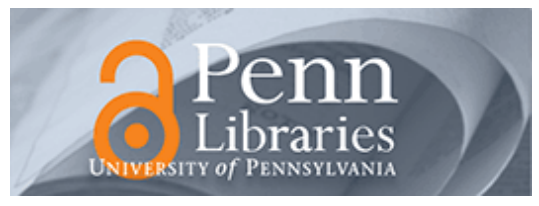

University of Pennsylvania

ScholarlyCommons

Health Care Management Papers

Wharton Faculty Research

$11-2011$

\title{
Medical Spending Reform and the Fiscal Future of the United States
}

Mark V. Pauly

University of Pennsylvania

Follow this and additional works at: https://repository.upenn.edu/hcmg_papers

Part of the Health and Medical Administration Commons, Taxation Commons, and the Taxation-

Federal Commons

\section{Recommended Citation}

Pauly, M. V. (2011). Medical Spending Reform and the Fiscal Future of the United States. Wharton Health Care Management, Retrieved from https://repository.upenn.edu/hcmg_papers/7

This is a conference paper presented at "Defusing the Debt Bomb: Economic and Fiscal Reform" that took place from October 6-11, 2011 at the Baker Institute for Public Policy, Rice University. This version is an updated and revised draft from November of 2011.

This paper is posted at ScholarlyCommons. https://repository.upenn.edu/homg_papers/7

For more information, please contact repository@pobox.upenn.edu. 


\title{
Medical Spending Reform and the Fiscal Future of the United States
}

\author{
Abstract \\ The rate of growth in medical spending in the United States and most other developed countries is high \\ most of the time, and is commonly higher (over the long term) than the rate of growth in GDP. Because \\ much of medical spending affects and is affected by government spending and taxation, the growth in \\ this share of consumption expenditures is both more important for fiscal policy and raises more potential \\ problems than consumer spending growth in other sectors of the economy. Given the growing \\ importance of the major federal programs Medicare and Medicaid in the US budget, and the impending \\ health reform expansion in Medicaid eligibility and insurance subsidies for Exchanges, federally-financed \\ spending growth has developed a major challenge to present and future fiscal stability. In addition, the \\ strong role played in private insurance markets by federal tax, spending, and regulatory policy means that \\ even private spending growth is a matter of fiscal policy concern. We know there is a problem, and that \\ current policies are not sustainable. But designing solutions that will do more good than harm requires \\ both a clear idea of the causes of the problem and a precise and politically feasible articulation of our \\ social goals concerned with medical care use, health insurance protection, and health outcomes of \\ Americans. In this paper I will describe the problem and talk about solutions. \\ Disciplines \\ Health and Medical Administration | Taxation | Taxation-Federal

\section{Comments} \\ This is a conference paper presented at "Defusing the Debt Bomb: Economic and Fiscal Reform" that took \\ place from October 6-11, 2011 at the Baker Institute for Public Policy, Rice University. This version is an \\ updated and revised draft from November of 2011.
}




\title{
MEDICAL SPENDING REFORM AND THE FISCAL FUTURE OF THE UNITED STATES
}

\author{
Mark V. Pauly \\ Bendheim Professor \\ Health Care Management Department \\ The Wharton School \\ University of Pennsylvania \\ 3641 Locust Walk \\ Philadelphia, PA 19104 \\ U.S.A.
}

Paper presented for "Defusing the Debt Bomb: Economic and Fiscal Reform"

October 5-6, 2011

Tax and Expenditure Policy Program, Baker Institute for Public Policy

Rice University

Houston, Texas

Final Draft: November 14, 2011 


\section{Introduction.}

The rate of growth in medical spending in the United States and most other developed countries is high most of the time, and is commonly higher (over the long term) than the rate of growth in GDP. Because much of medical spending affects and is affected by government spending and taxation, the growth in this share of consumption expenditures is both more important for fiscal policy and raises more potential problems than consumer spending growth in other sectors of the economy. Given the growing importance of the major federal programs Medicare and Medicaid in the US budget, and the impending health reform expansion in Medicaid eligibility and insurance subsidies for Exchanges, federally-financed spending growth has developed as a major challenge to present and future fiscal stability. In addition, the strong role played in private insurance markets by federal tax, spending, and regulatory policy means that even private spending growth is a matter of fiscal policy concern. We know there is a problem, and that current policies are not sustainable. But designing solutions that will do more good than harm requires both a clear idea of the causes of the problem and a precise and politically feasible articulation of our social goals concerned with medical care use, health insurance protection, and health outcomes of Americans. In this paper I will describe the problem and talk about solutions.

\section{Why is there a financing problem? An arithmetic explanation.}

Before talking about the content and effects of medical spending, let us first view it as a macroeconomic accounting issue. In economies with growing real income, consumers usually want to spend more on almost all items of consumption from one year to the next; goods and services are usually (in economic terminology) "normal." It is not abnormal that some categories of spending may be more responsive to growth in income than others. I may want to spend a disproportionate share (relative to my current 
spending patterns) of any increase in my income on some categories of spending. ${ }^{1}$ That is, consumers may choose some goods to be "luxuries" in the sense that their percentage spending growth exceeds the percentage growth in income.

For goods demanded and paid for privately, no problems are raised by such behavior. Spending shares rise for some things as people pay for what they want. But if luxury goods are financed by government, there is a mathematical proposition that may be a problem. Since the tax base grows at approximately the same rate as income, an increasing share for a given component of spending necessarily implies higher tax rates year in and year out to finance that spending unless spending shares on other types of public activities are to shrink or deficits are to become even larger. Ever-growing marginal tax rates are a public finance economist's worst nightmare.

So far, medical spending seems to fit into the luxury category, for reasons we will presently discuss. There is nothing illogical, or wrong, or problematic about a category of private consumer spending that grows more rapidly than income over a long period of time (except that this cannot persist forever). Were medical spending fully privately financed, such spending growth need not be a cause for concern and might even be an object of cheer, as a growth industry in an otherwise bleak economic landscape. But because so much medical care is publicly financed, the inevitable and inexorable rise of its tax burden as a percentage of income and of the tax base means that it upsets fiscal stability and political equilibrium. I will argue both that this characteristic of medical care demand, one which is wholly natural and not anyone's fault, is the main source of the fiscal problem when medical services are publicly financed, and the main reason why that problem is close to intractable without major and wrenching political choices.

\footnotetext{
${ }^{1}$ Across households at a given point in time, spending appears to rise with income (controlling for health status and insurance coverage), but not at a rapid rate. It is the way spending grows with increases in income for a given set of households that is being discussed here.
} 
While it is not necessarily easy for people to adjust their private budgets to accommodate spending items they want to increase, they do it all the time. The problem is that income tax rates (or any tax rates on a base correlated with income) are under strong pressure to increase to pay for what people want-even if the number of eligible persons, their age distribution, their illness levels, and all other things remained the same. The political system is much more challenged to increase tax rates (or make other accommodations), and, from an economic point of view, at some point should stop doing so.

In what follows I first outline what we know about the reasons for this challenge for the medical care system as a whole, discuss why it is much more serious for the public sector (but also why it is hard for public and private sectors to adjust differently), and then talk about potential "best of a bad lot" remedies to the fiscal problem.

\section{What is special about medical care spending?}

It may come as a surprise to hear that, at the heart of the problem of medical spending growth, is good news: At least on average, American real incomes per capita have been rising and continue to rise. American medical care (up to a point) is good for you, and gets better every year. Not surprisingly, when people experience a rise in real income, one of the things they want to be able to do with that income is to increase their health-in the jargon terms of health policy, to increase the quantity and quality of their expected life years. We want to spend some of the happy increase in real income on living longer and better.

There are two things our health care system, flawed as it is, can do to improve our health. First, at any point in time there are additional treatments, compared to what most people are getting, which can improve their health yet further. Effective care for most people includes routine pediatric care, monitoring, screening, checking, and counseling for chronic conditions and, on rare but important 
occasions, serious if expensive treatments that really work. Whether the additional treatments would produce enough of an improvement to be worth their cost is still an open question, but there are always useful things at the margin.

Second, each year new treatments, new procedures, and new approaches that generally work better, at least for some people some of the time, are added to the armamentarium. This "technical change" especially characterizes the research driven medical care industry. Putting these two benefits from more medical care together, most people decide that it is worthwhile to have more spent on them when growing income allows it - and the increase in desired spending is usually a larger percentage amount than the increase in income.

This is not the only way to look at spending growth related to new technology. While growing income probably stimulates and surely facilitates the spread of costly new technology, some analysts believe that technology itself has an exogenous influence of its own - what is usually called the "technological imperative" (Fuchs 2011). The idea is that, if they invent it, physicians will offer it and consumers necessarily will come whether they want to or not. There is plenty of evidence that increased demand stimulates the progress of given technologies but it is surely true that innovative discoveries do matter when they happen (Finkelstein 2003), and do slow spending growth when they do not-as evidenced by the recent slowdown in introduction of new drugs and drug spending as fewer blockbusters have been discovered. While sorting out cause and effect here is potentially important, the key fact is that the growth of spending outpaces income, regardless of its cause, and that is what I will take as given here.

As already noted, people want to spend a larger-than-previous share of spending on their health, while still spending more, just not disproportionately more, on other items of consumer spending. When my income grows I add a big screen TV, a more luxurious vacation destination, and an extra night out-but compared to these things I want to bump up my medical care use even more. Of course, medical care is 
different: I have some choices to make about buying care at the point of service by paying more out of pocket, but mostly this increase comes about as I choose a more permissive health plan and accommodate my health plan's willingness to reimburse for better care by paying higher premiums .

Less transparent in this story is what happens to public spending, especially the major public insurance plans Medicare and Medicaid. Empirically, the evidence is pretty clear on Medicare: its spending growth per covered person tracks closely privately insured spending growth, and as well the total spending (including out of pocket payments) of Medicare beneficiaries tracks well the path of private spending per privately insured person (though of course the level of average Medicare spending is much higher because its insureds are older or disabled) (Boccuti and Moon 2003). If there is any regularity here it is that Medicare spending is a little less "inflated" than private spending, but there is no major gap that has emerged over time (despite occasional overages and underages in terms of reimbursement, coverage, and spending).

With Medicaid things are less clear. Medicaid can and does follow different paths from the average in different states, partly in response to changes in the number and composition of the poor and near poor people Medicaid covers, and partly because its generally lower reimbursement policies means that it does not pay as much for as much use as the rest of the population (Grannemann and Pauly 2010). There is lower cost (than if payments were greater) but less access. The divergence between Medicaid and other health care spending historically has been uneven though undramatic, but there is little doubt that Medicaid-and especially the 51 different Medicaid programs in the states and DC - can and sometimes do march to a different tune than that played by health care as a whole. That is, faced with budgetary crises, individual states do bite the bullet and cut or dramatically slow Medicaid spending per beneficiary; on those rare occasions when the budget permits (think tobacco money), they sometimes make it a little more generous. 
The point so far is that the largest single share of medical spending growth per capita is fueled by this demand-driven health-improving but expensive technical change-both new products and new (and greater) use of existing products. The second major contributor to medical spending growth has been prices. However, because medical care is a labor intensive industry, the bulk of these prices increases are translations of wage increases, and wage growth in the health services sector has outpaced wage and price growth in the rest of the economy. There are some exceptions to this wage-based explanation: rising drug prices mostly benefit drug firm stockholders and scientists (and dramatic price declines when things go generic harm them), and some (small) fraction of rising insurance premiums goes to insurance firm executives, for profit and nonprofit. But still, what we know to be responsible for spending increases are mostly wage increases-almost all of which are paid to American workers. Health care is not like oil, or even computer software. We are paying a lot more but much of it goes to better care and better-paid American workers.

Noticeably absent from this catalog of "what we know" about spending growth is evidence that inefficiency is a cause. An important first point: while there surely is inefficiency, waste, fraud, corruption, and general goofing off in health care as there is any industry, and while (more seriously) inefficiency is probably higher in this industry than in some others, to predict higher spending growth we need to have reasons to believe that inefficiency is getting proportionately worse every year-and that we do not know. And there surely is some inefficiency in growing spending. But the data on variations in spending across countries or states in the US does not help us to know what is happening to changes in spending over time, and there is little more that is definitive on this subject (Skinner 2011).

Thus the discussion in the Rivlin-Domenici report (Rivlin, Domenici et al. 2011) that first asserts that "slowing the growth in health spending is realistic" and then points to lower spending and better outcomes is other countries is not really logical; there may be some things about other countries we 
should copy to lower our level of costs, but the data on growth of spending or GDP share (depending on the time period chosen) puts us below many of our peers. Another example of this confusion from Rivlin-Domenici (p. 44): the assertion that fee for service payment (mostly now limited to traditional Medicare) is a major reason for rising spending because it offers "incentives to amplify the volume of tests." If the payment rate for tests is set too high there will be incentives to do more of them, but once the volume is boosted, there is no reason why fee for service payment means that it should continue to increase as time goes on.

There are some other causes of spending growth that bring up the rear. Total spending obviously grows with the population, but the fact that births and net immigration exceeds death in the US is not something that most people would want to change. Spending per capita grows as threats to health grow; the primary threat is older age, with the whole (and intertwined) list of obesity, HIV, asthma, and depression. It is not clear that we would want to change the fact that more Americans are living longer, and I would not want to change the fact that productive immigrants are trickling into the US. We would like people to stay more fit, have better lifestyles, take fewer health risks, and breathe better, but cost effective ways to effect those changes have so far proven elusive-and it is important to remember that in total, despite worsening of health in some dimensions, we are still living longer and better than we ever have.

\section{Working out the math.}

The story so far about health and wellbeing is pretty positive. Despite some flaws in our health care system, it does deliver better care to more people every year. Not only that, but in aggregate and on average, the value of this better care is probably greater than the additional real resource cost of this better care (Cutler 2004). Problems arise, however, when we start to break this virtuous inequality 
down into its component parts, and then when we try to extrapolate it into the future. I will subdivide first by dividing the population by age and income (to parallel our major social programs for medical care and medical insurance), and then by talking about the relationships between those component parts. I will talk about aggregated total spending and then about how that aggregate does or does not hide differences in how these different parts of the population experience and are affected by spending growth.

\section{Medical spending's share of GDP and other useless and useful statistics.}

It is commonplace to begin any discussion of the relationship of medical spending to fiscal policy with the larger issue of the relationship of total medical spending, tax-financed and not, relative to GDP, and to cite the observation that for decades medical spending relative to GDP has been higher in the US than in any other country in the world. The usual inference or implication is that we must be doing something wrong, especially since our health outcomes are not superior to many of those in other developed countries. Of course, "doing something wrong" is meaningful only if someone has some idea of something we really could do differently; maybe we are just unlucky or stuck in a place we cannot change.

Some of the difference does reflect something other than bad behavior about resource use. A large fraction of the difference between the US share and that of other developed countries (probably more than half although precise measurement here is hard to do) results from that fact that, at exchange rates based on overall purchasing power, medical care prices for many things are much higher in the US than anywhere. But it is even more important to note that the bulk of higher prices (with drugs as a probable exception) are caused by wages for medical workers - physicians, nurses, and even unskilled hospital workers-being higher in America than anywhere else (Pauly 1993; Anderson et al. 2003, 2007; 
Laugeson and Glied 2011). The mirror image is that the share of our workforce in health care is not out of line with the share in most developed countries. We spend more not because we hire more people into health care and away from other industries but because we pay them more than other countries do. There may be more capital and equipment, but that difference is not enough to close the gap.

We pay more for two reasons, both of which would be hard to change. In other countries the government usually is by far the major buyer of health care and uses this large buyer market share to hold down the prices and wages it pays; in the US those prices are determined in relatively free labor and product markets. The other reason is that we pay more for people to work in health care because we pay more to workers generally - and health care wages have to keep up. In short, we could have a much lower spending share if we were like the UK used to be: a nationalized health care system in a low productivity economy. No one would want that. There might be a case for tightening the payment screws on drug companies and doctors, but their profits or net incomes are only about $15 \%$ of our total spending, not enough to make a big dent-and more importantly, not enough to slow the growth rate for very long.

My main point here is that medical spending data, no matter how accurate, provide a very poor indicator of resource use for medical care, and it is real resource use relative to real benefit that is relevant to determining what might be better for the economy. Payments in excess of real resource use may be unfair, but they are really only transfers from consumers of medical care to producers of medical care, and, in contrast (say) to other markets where we pay more, like oil or rare earths, the excess payments almost all go to Americans.

There are other reasons why the health spending GDP share is one of our most misleading statistics. The level of GDP obviously affects the ratio, but it is under the control of Dr. Bernanke (if it is under anyone's control), not of any medical doctor. Moreover, since shares must add up to $100 \%$, if the US 
medical spending share is regarded as excessive, some other developed country with a below-average share (like Japan) must by definition have excessive spending on some other item of consumption. (In the case of Japan it is housing.) Why doesn't that overspending harm the Japanese economy? At this level of generality we can only ask these debater's rhetorical questions, but they bring us back to the main point above: correct evaluation is not helped by the misleading share data, and instead should be based on asking about comparative value of resources used in medical care versus what those resources could have provided if they were used elsewhere (assuming it is possible to use them elsewhere).

A more meaningful statistic begins with a first difference: it is better to compare the rate of growth in medical spending with the rate of growth in GDP. Such a comparison drops out those unknowable and irrelevant cross national differences in how well medical people are paid and other special characteristics like consumers' life style. Of course, it would be better to convert both GDP growth and medical spending growth to real terms, either resources or consumption. As long as price changes can be assumed to be the same in medical care as in the economy as a whole, however, even comparing nominal growth rates is helpful.

In addition, growth rates are the indicators used by Medicare's trustees and most policymakers (including President Obama) to describe different scenarios. Roughly speaking, medical care spending in the US has a long term trend of growing at a rate about 2-3\% above the rate of growth of GDP; policy proposals often target to cut to GDP $+1 \%$ (because that postpones the date at which medical spending will eat up all annual GDP growth by about fifty years), or in the most ambitious cost containment programs of health reform, to GDP growth only. This framing also allows us to bring back the notion of medical spending as an historical luxury good (since that implies a growth rate above GDP).

In both the actuarial calculations in the Medicare Trustees' Report and the policy proposals, the "overGDP" growth rate is just treated as a policy parameter for the entire medical economy which "we" can 
choose as we wish. My earlier discussion implies, in contrast, that as individual consumers we have already chosen the high rate of growth-so any collective choice of a lower rate is bound to require some give (and probably some stress) somewhere. One partial resolution of this dilemma is to note that, at least as of this writing, governmental policymakers are not in the US responsible for or permitted to choose everyone's medical spending growth rate. If you are in the private sector, you are allowed to spend your own money on your own health care to whatever extent you wish, foolish though that may be. This choice is not entirely independent; almost all of us with private insurance obtained through a job actually get a substantial tax break that encourages us to spend more than we otherwise would. But what upset Harry and Louise at their Clinton-health-reform kitchen table was the prospect that the Clinton plan did have, as a last resort, a provision for the government to cap total spending, and even so left-of-center a commentator as Paul Krugman reminds us that is not as if the government is ever going to stop us from spending our own money (Krugman 2011). (One notable exception is for Medicare beneficiaries who take the government Part B plan; they are not allowed to pay a doctor more than Medicare permits, no matter how grateful they are or how much they want to get to see that doctor.)

The focus on overall medical spending growth was adopted by the actuaries because of the long term high correlation with Medicare already noted, and because decades in the future it is more plausible that one can forecast overall trends rather than individual components. But a key question is about this linkage: is it inevitable and, if not, is changing it either feasible or desirable? Here is where the argument is going: it is plausible that if Americans' real incomes continue to grow (and return to their long term trend), they will want their private insurance and medical care spending to continue to grow as a luxury good, just the same as it always has. But Medicare can no longer sustain the taxes that would allow it to keep up. So either the link between Medicare and private spending has to give, or the government has to limit private medical spending. The key question is whether it is either thinkable or 
desirable to use different and more differentiated models to predict or describe future medical spending trends. That is a political question, not a statistical one, and it is what we turn to next.

\section{The dire fiscal future for Medicare, and the effect of tax financed medical spending on the federal}

\section{budget.}

Federal actuaries are required to forecast future spending on Medicare with as much accuracy and realism as they can muster. For this reason, and because Medicare is the largest single category of medical spending in the federal budget, its fate is usually used to proxy what medical spending means for the government budget as a whole. So here I first give more detail on those projections-but then I turn to either items which will become increasingly important if health reform is implemented as planned-Medicaid (financed jointly by the federal government and the states)--and federally financed subsidies to insurance purchases in federally regulated exchanges (after 2014).

Part A (hospital) spending under Medicare is financed by payroll taxes going into a trust fund. At present that spending is a little more than half of total Medicare spending with a growing share (a development which requires the Medicare trustees to report on what they will do to get the general revenue funded share of Medicare back under $46 \%$ of total spending). However, although the Part A share is falling, the level of Part A spending is growing, and it is growing more rapidly than forecasted tax revenues (and has done so since 2008). The Medicare Trustees conclude that Part A is not even "adequately financed" for the next 10 years (despite increases in Medicare taxes in the Accountable Care Act $[A C A])$, and things become even worse in the longer term projection. The balance in the trust fund is shrinking, is forecast to hit zero in 2024 , and will be in serious deficit thereafter unless spending is curtailed; the deficit at the end of the 75 -year projection period will be $0.8 \%$ of the payroll tax base (on an overall tax rate of 2.9\%)-about a third of total financing (Board of Trustees 2011). 
Parts B (physician) and D (prescription drugs) parts of Medicare are financed by general revenues, but their growth probably will be even more rapid. GDP is forecasted to grow at $5.2 \%$ over the shorter term projection period, while Part D will grow at $9.7 \%$ and Part B at $7.5 \%$ (ignoring the unlikely event that Congress actually implements drastic physician pay cuts already in law but always postponed).

Putting these forecasts together, total federal spending for Medicare as a \% of GDP is projected to double over the next 20 years, and to potentially triple after 75 years: from its current level of $3.6 \%$ (2010) to $6-11 \%$ in $2050-2085$. After a short run period where forecasts depend on current law, these projections of Medicare spending are driven by projections of the growth of total medical spending in the US. Until recent years, such long term spending was based on a simple prediction that it would grow that the rate of GDP plus 1\% until 2085 (and then at the rate of growth of GDP thereafter, if anyone cares). Now the excess growth is forecasted to start out higher and to trend down to zero by 2085 , but with the same average excess of $1 \%$ over the period.

Provisions in the ACA contemplate further reductions in Medicare reimbursements and spending growth from the IPAB, down to as low as $0.5 \%$ over GDP, but these have not been built into the forecasts. That is because the Trustees are not certain that there are ways to reduce spending. They speculate: "It is possible that health care providers could improve their productivity [and] reduce wasteful expenditures... For such efforts to be successful in the long range, however, providers would have to generate and sustain unprecedented levels of productivity gains... The ability of delivery and payment methods to significantly lower cost [sic] growth rates is very uncertain..." (p. 41).

\section{Medical spending and the budget: data for looking backwards and forwards.}

As already implied by the Medicare Trustees' report, the rapidly increasing growth of federal health care spending is posing problems for that important program. A good way of getting an idea of what past 
spending growth has meant to the overall public budget is to examine Figure 1, drawn from the work of Chris Conover of Duke University.

\section{1b | Between 1966 and 2007, all of the increase in the size of government was attributable to growth in tax-financed health care}

Government Spending as a Percent of GDP

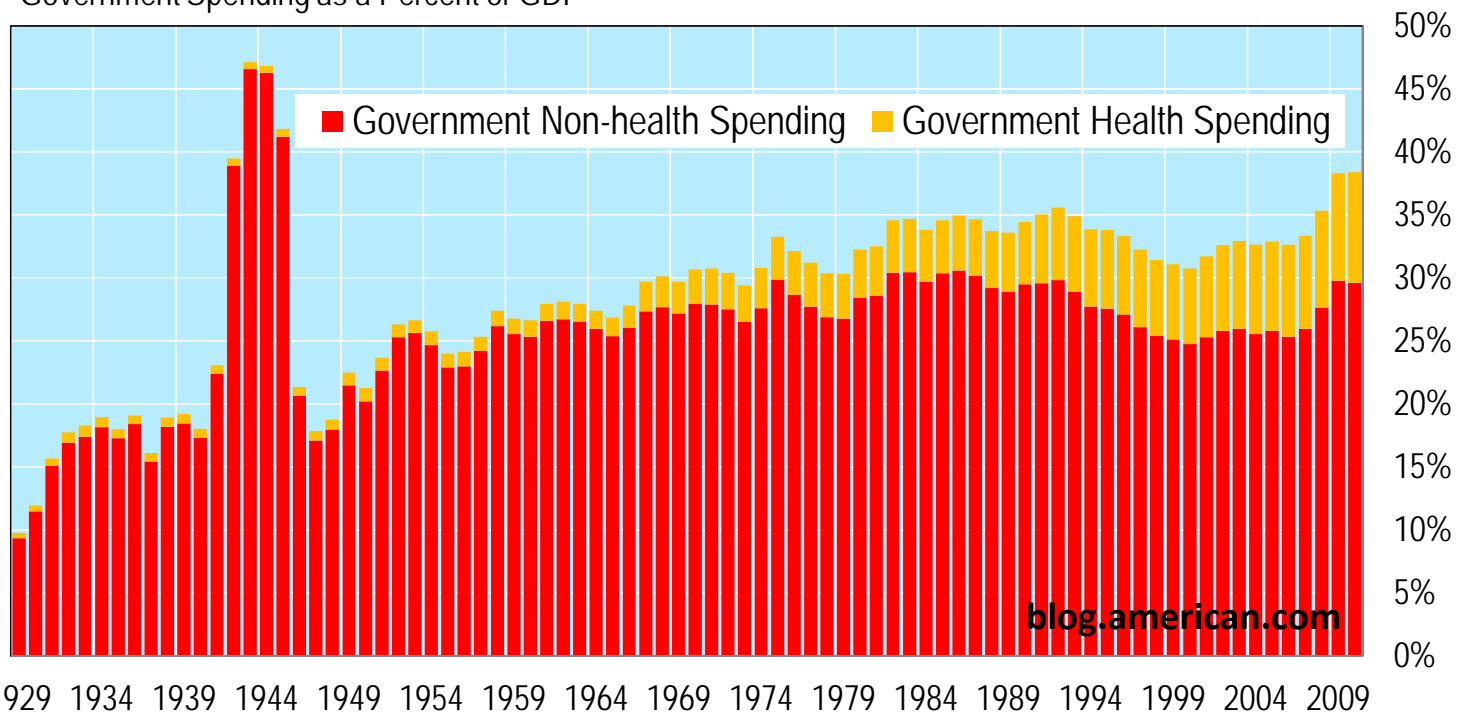

Note: Data include debt service, but the entire amount appears under non-health spending. If allocated by shares of spending, this would increase government health spending and reduce non-health spending.

Figure 1. Reprinted courtesy of Christopher J. Conover and AEI Press from "Health is the Health of the State," The American, 19 July 2011. http://www.american.com/archive/2011/july/health-isthe-health-of-the-state (accessed 26 Sept 2011).

Not only does the chart show the increasing fraction of GDP going to tax financing for medical care at all levels of government since the passage of Medicare and Medicaid in 1965, it shows that this increase is wholly responsible for the rising share of public spending in the economy as a whole. Some analysts have been disturbed about the increasing importance of government in the US economy, fearing a transition to a European-style welfare state; others are less concerned about or even favor higher social 
spending, and note that the increasing spending share has not yet been matched by as large an increase in the taxation share because of the budget deficit. This diagram makes the important point that, whatever your political philosophy, in reality government spending growth has been all health care all the time. Leviathan wears a white lab coat.

The effect of this growing spending has been that Medicare, Medicaid, and the Medicaid-related Children's Health Insurance Program made up $21 \%$ of the FY2010 federal budget. Add to that the $20 \%$ for Social Security and $6 \%$ for interest on the debt, and half of the budget is already gone before discretionary and defense spending can be even considered. Looking forward, as the two fiscal reform commissions have noted, this pattern will continue: projected growth in federal funding for medical care, Social Security, and interest on the debt will eat up virtually all of any forecasted increased tax collections at current tax rates, especially later in the decade when the politically controversial patches in Medicare doctor payments and payments to HMOs cease to have effects.

\section{Can we cut long-term spending growth while improving the quality of care?}

The Medicare Trustees' report gives us the simple answer to this question: Nobody knows for sure, but it has never happened in history up to this point in time. I will now argue that, while hope springs eternal, the answer for the future is also more likely to be negative than positive. The reason for a negative answer goes back to the earlier discussion of causes of spending growth - the most direct way to lower spending growth would be to lower the rate of growth of beneficial but costly technology or of wages. Doing the first will probably harm quality - for someone, in some dimension. Slowing spending growth by cutting raises for doctors and nurses and reducing increases in insurer and drug company profit need not harm quality, but here again one may wonder whether health workers or investors will really be willing to do more for less-and those would not be reductions in real resource costs. Just 
wishing, or even demanding, that the system provide higher quality lower cost care is not going to get you there, and yet much of the policy discussion does consist of observations that because this kind of change is so needed it will be made to happen.

One important benchmark: when we talk about "improving quality," do we mean "compared to last year," or do we mean "compared to the improvements that would otherwise have happened"? Expecting that our health care system continue to improve life expectancy is not asking too much, because (with just a few blips) it has been doing that all along. And logically, if we held real resources just a little above where they are today (setting aside higher-than-average changes in medical prices) we could maintain or get a slight increase in life expectancy with lower spending growth and roughly constant tax rates to support federal programs (Pauly 2004). But I am going to assume that bringing improvements in health technology nearly to a standstill in order to save money is not what people want. Rather, they want to get even more and pay even less. This is the hard order to fill.

We do have evidence that it can sometimes be done. I am most familiar with work looking at the impact of specially trained nurses helping hospitalized Medicare patients make the transition back to the community (Naylor et al. 1999). Using very rigorous designs, that work shows that this intervention can substantially reduce the rate of readmission to the hospital and the adverse health outcomes that either trigger or follow from it; we can save money and improve the quality of life. Some (though only a few) immunization programs using low cost vaccines can also save more than they cost because they prevent illness and save lives; progress on this score stopped with the chicken pox vaccine. More speculatively, there is some reason to believe that greater use of some prescription drugs for asymptomatic chronic conditions like high blood pressure-if only we can get people to use them-can produce "cost offsets" by cutting the cost of physician and hospital care and keeping people healthier. The problem is that these things known to work and save money are not enough to offset the upward push of other things 
known to work that cost money-and hard-won changes also do not produce continuous reductions in the rate of spending growth, only in its level as they are phased in.

There are many other discussions of prospects of saving money and lives, but little work that has the two key characteristics of proof of efficacy (not just an observation that somebody has lower costs and better outcomes, with no causal connection) and proof that they can actually be implemented in large scale practice. The absence of evidence is not evidence of absence, so we have to temper pessimism here, but it is still worthwhile to be skeptical. Let me give two examples where doubt is warranted (though hope should never disappear).

One example may be broadly defined as "reorganized integrated delivery systems." These are systems which typically started as large multispeciality physician group practices that affiliated with or built hospitals and other capabilities to cover the full range of a defined voluntarily enrolled population's health care needs. Typical examples are the Mayo Clinic, the Geisinger health system, and the Kaiser health system. While not all similar entities are equally admirable, these are the examples frequently presented to show that cost and quality need not trade off. But what do these stories prove? Investigations of how good performance is achieved have failed to identify a parsimonious list of design features consistently associated with better outcomes. Instead, qualitative factors like "physician culture" or "leadership" are usually what one ends up with after discarding the objective measures that do not work (Gawande et al. 2009). When these factors are not tautological, they suffer most from our lack of knowledge of how to produce them, or how to change them where they do not exist. There may only be a small fraction of the physician workforce psychologically predisposed to be able or willing to work as well together as in these good examples-at least, no one has shown how to manufacture a culture of cooperation and allegiance to evidence-and leaders are famously born, not made. One might try (and the Obama administration is trying) to put the rewards and the information in place to 
bring those who work well together or lead in the right direction out of the woodwork, but there is no evidence that would lead one to expect success.

The other example comes from the other end of the political spectrum: the argument (Rivlin, Domenici et al. 2011) that "competition among firms will improve the quality of care and increase efficiency." Economic theory does say that competition is a good thing for consumer and producer welfare (if it can be fostered), but the most it says about quality and cost is that competition should lead to the lowest cost for a given quality, or the highest quality for a given cost, but not that (compared to the absence of competition, one assumes) that it will necessarily produce more of both. All we can say in theory is that, compared to unregulated monopoly, unregulated competition cannot lead to the combination of higher costs and worse quality. We cannot say anything in theory about how unregulated completion will compare with regulated markets (monopoly or competitive). There are surely many examples where regulated monopolies produced too high a level of quality at high prices (air travel in the prederegulation era, and "Cadillac-quality" physician care from the AMA), and some where it produced very low cost but low quality and availability (federal vaccine programs).

This absence of theoretical certainty is, I hasten to add, not a reason to be unenthusiastic about competition, and there are a few minor examples in health care credibly cited as evidence that unregulated competition can function rather well (plastic surgery, radial keratatomy). The magic might work for more of health care, but it might not. Certainly there is no evidence that the informal data on variations in cost for given outcomes used to document inefficiency (e.g., the variations across countries or across geographic areas in the US) find the most competitive markets at the high quality/low cost end of the spectrum. We should have competitive markets to be sure we have maximized our chances for a good deal, but we should not expect magic from their introduction, at least not along all dimensions of 
desirability. Somebody should give it a shot, but the rest of us should hold back and see how it goes. More about this later.

\section{Cutting a little to save a lot.}

If the jury is still out on the possibility of magic, is there something less exciting but surer we can contemplate? Here the answer is "market change is probable, if politics will allow it." What I have in mind here is what has happened in many other industries: a process of destructive innovation which, shorn of rhetoric and spin, means sacrificing some dimensions of quality to a modest extent in order to save a lot of money. In the classic business school studies this has happened in the copier industry, in the airline industry, and in many other places (Pauly 2011).

I have to admit that examples of even these arguments apply more convincingly to things that change the level of spending (and therefore growth temporarily), rather than the long run rate of growth. So I will first provide the "levels" examples and then see how they can be extended to growth rates. Minute clinics are an example of what I have in mind. The nurse practitioners who staff them are usually very capable, and probably better at some tasks than the typical primary care doctor, but they cannot provide as wide a range of services. No harm in that; a skilled chef cannot advise you on your wine. As long as buyers and sellers know where the limits are, things can be much less costly, and even better in many dimensions-but one-stop shopping for all possible primary care needs will be a casualty.

For some unique political and economic reasons this particular and egregious example of slightly lower quality and much lower cost did successfully enter the market-though its growth is now stalled. However, I believe that regulation, law, and custom prevent a much larger and more desirable shift to this way of thinking and style of care. It is just not yet acceptable for middle class people to talk about 
anything but the best health care, and legal liability may prevent emergence even of what they would accept.

How can this concept be applied to technical change? To be specific: could a health plan announce that henceforth its premiums would increase only at GDP plus one percent, and get there by paying current prices but buying less than the best new technology? Perhaps, but such an innovation would surely face serious challenges. So far, private insurers and hospital systems have been unwilling to go first. (Drug stores are the pioneers.) And the timing may not be right for now.

\section{The real reason to limit public spending, and the results for two-class medicine.}

I have already shown some of the fearful numbers about the impact on the federal budget or GDP shares if medical care spending trends continue. But what if that kind of growth is what people want because it is worth it to them? That high medical spending growth is natural is what both history and sophisticated econometric studies tell us. So why not just plan on doing whatever needs to be done in the federal budget-spending cuts elsewhere or tax increases-to accommodate what citizens desire? That they would prefer to have this outcome at less cost makes for good politics but bad economics; taxpayers should just face the reality of ever-higher taxes and like it.

The flaw in this Panglossian argument is that there is something special about publicly financed spending, even when it goes for the same things that people buy privately. That something, as I noted some time ago (Pauly 2003) is that fact that all practical tax systems impose an additional cost of moving resources from the private to the public sector-what is called the "excess burden" of taxation. It is this additional cost, one that increases exponentially as more resources are shifted, that limits both what government could and should do. 
The argument is classic. If (at age 70) I were to choose to buy a private health insurance policy, I would pay a hefty premium by diverting part of my income or assets to the purchase. I would incur a cost in terms of what other consumption I would sacrifice. Presumably I would have saved more when I was younger to be able to do this. But that would be the end of it. I save, I accumulate, I spend-all voluntarily.

Suppose in contrast I am taxed to pay for Medicare, and suppose it just happens that my tax share to finance my Medicare insurance equals what my private premium would have been. (I must be a somewhat better-off-than-average and still-working senior citizen for this to happen, given the approximately $90 \%$ subsidy to Medicare.) I envision the same cut to my other spending, but now I do not take this cut lying down. Instead, I look to see if there are ways I can reconfigure my income and assets to avoid having to pay so much. I might shift to tax exempt bonds, invest in real estate, or just spend less effort consulting and writing (offset by more leisure, so it shouldn't be a total loss). This distortion of behavior to avoid taxes applies as well to the younger generation; even though they know that Medicare needs their taxes to pay off existing seniors and to be around for them when they retire, they are individually better off trying to figure out how to pay as small a share of the bill as possible. As I and all others behave this way, not only does the tax base shrink, but people do inefficient thingsinvestors invest in inefficient things, women and teenagers stay out of the labor market, and everyone hires tax advisors - so the total economic pie shrinks.

Not only that, but this excess burden cost increases as a proportion of additional tax revenues with the square of the marginal tax rate-it increases at an increasing rate. When tax rates are low, the "wedge" between what things really cost or yield and what people experience is small, so decisions are little distorted. But as the tax rate rises this distortion gets worse and worse. 
Current estimates of the average excess burden of the federal tax system currently are in the range of 25 to 50 cents per dollar of revenue collected. Excess burden maps the age-old tradeoff between equity and efficiency; a tax instrument in which people at different income levels pay their "fair shares," like the progressive income tax, generates more excess burden than a proportional or capped tax like the payroll tax. The growth in this cost can be striking. A recent (though conjectural) estimate of the long run marginal excess burden cost of the subsidies in health reform indicates that, if financed wholly by surcharges on the income tax, excess burden will run up to more than $200 \%$ of taxes collected (Baicker and Skinner 2011).

The upshot is that there is a serious extra cost from expanding public financing; it is not a matter of neutrality whether the same benefits for the same people are financed publicly or privately. It is worse if you pay for health care through taxes than if you voluntarily withdrew the money from your wallet or purse. Logically this additional cost should imply a greater need to bring tax-financed spending growth to an end-which leads to the key conjecture that, once this cost gets high enough, voter-taxpayers may choose to spend less in this form. While the theory about and the evidence for excess burden is strong, measurement of its magnitude is much more speculative. Moreover, evidence that its existence and size affects collective choices is also speculative. But it still seems worthwhile to spell out the concepts of what taxpayers ought to choose to do when faced with an ever-increasing inefficiency cost to ever increasing public spending, and what they might be forced by reality to do.

The impact of excess burden on ideal publicly financed medical spending in the federal budget: issues and options.

The argument so far is that excess burden should constrain the extent to which tax financed medical care grows over time, moving it to a lower level and different rate of growth than private spending. We 
usually assume that the federal tax base broadly defined grows at the rate of growth of GDP. This means that a spending category that is growing faster will impose ever-increasing excess burden costs even if the rest of federal spending grows at the rate of GDP. A higher rate of growth for the remainder raises excess burden even more across the board.

Without any additional constraints, the conclusions are clear: not only should less be spent by government in any year than if financing were private, the amount should rise less rapidly with income than it would if it were privately financed. The simple manifestation of a policy that takes this concept into account is the voucher model, especially for Medicare. This idea, in several different versions, has been around for a long time. There are several variants. The voucher may take the form of a uniform predetermined dollar amount, or the dollar amount may vary (usually inversely) with income or wealth. Sometimes the voucher-like arrangement takes the form of a matching subsidy (up to a limit) (Pauly 2008). The definition of what are qualified plans, how they will be priced and sold, whether there should be a publicly produced option, and a host of other details also need to be considered.

Here, however, I want to emphasize two options and then talk further about their political desirability and feasibility. One option, probably the most common, imagines that the voucher is a predetermined amount which can be legally and easily supplemented by a client's private spending should the client choose to do so. The other option limits this supplementation to a greater or lesser extent: by forbidding "balance payment" entirely, by capping the options for supplementation, by making supplementation a regulated and constrained market. Neither option is anywhere nearly as attractive as today's Medicare, but today's Medicare is unsustainable.

Either way, there is one common characteristic: the dollar amount of public spending for vouchers or subsidies should grow at a rate that is politically chosen, even if this is a slower rate of growth than would otherwise have occurred for the nominal benefit package or packages available to recipients of 
subsidies. For example, if private insurance premiums for the unsubsidized population (actually a tiny fraction of Americans, as we shall see) are the benchmark, the public subsidy would potentially grow at a slower rate than these private premiums.

Analysis and opinions of the two options are strongly affected by views on diversity in medical spending and insurance coverage, a bland term for "two-class medicine" (or multi-class medicine). Some think that, even in (and perhaps especially in) a society where both resources to pay for health care and preferences for what kind of health care to get with those resources vary substantially over the population, allowing some to get more than others by spending their own money is unacceptable. Others take the view that public concern should be limited primarily to setting a floor of access or health outcomes below which no one should fall, but not to setting a ceiling above which none can rise.

This preference is based on ethical, not economic, principles. Simple economics would have regarded allowing demand variations, whatever their cause, to be manifested in what people get as an efficient outcome, given the distribution of initial resources; the inequity of allowing the rich to get more medical spending would be traced to the income distribution policies that allow the rich to have more resources in the first place. There are economic approaches that allow citizens to have preferences over the consumption of their fellow citizens, but they are complex and speculative.

\section{The tax exclusion and private spending.}

The fiscal consequences of growing medical spending discussed so far relate to government's role as a buyer of health care or health insurance for various client subpopulations. There is, however, another feature of public policy that affects both the budget and medical spending. There are a set of provisions in federal tax policy which allow a person's tax liability to be affected by what they do with regard to private health insurance and health care. The largest component of this set of influences is the tax 
exclusion for employment based health insurance. This exclusion takes two forms. One form is the exclusion from taxable income of the part of worker compensation used to pay the "employer share" of worker-only and family health insurance premiums. The other form is the exclusion from taxation of the worker's explicit premium for either kind of insurance if paid as part of a cafeteria plan which allows parts of wages to be set aside for payment for certain kinds of benefits. As a round number, the total "tax cost" of this exclusion at all levels of government currently amounts to about $\$ 200$ billion, which is about $25 \%$ of total premiums for employment based health insurance. (These calculations are all based on the assumption that the total payment for insurance comes from what would have been worker wages; in this theory the worker always pays $100 \%$ of the cost of insurance so there is no possibility (and no concern) about employers shifting the burden of paying for insurance to workers.) There are some additional tax deductions and exclusions allowed by law although their revenue consequences are much smaller: the exclusion of up to $\$ 4000$ per year in a tax shielded flexible spending account, deduction from personal income tax of high levels of out of pocket medical spending, and some tax advantages for Health Savings Accounts.

The potential impact of removing or capping these tax preferences on health insurance coverage is not negligible. Although estimates here are far from certain, a reasonable estimate is that removal of the tax exclusion, by causing people to choose insurance plans with higher levels of cost sharing, might reduce spending covered by group insurance from 10 to 20\% (Phelps 2003). This would translate into a reduction in overall spending of 6-12\%. Not only that, it would raise substantial additional tax revenues in a way that does not generate excess burden, and it would do so whether or not workers cut back on their coverage, since more taxes would be collected on payments for insurance if they did not cut back, or on higher taxable money income if they did. 
What is both more hopeful but more challenging is whether these cuts in tax subsidies would slow the rate of growth in addition to cutting its level. In theory, higher cost sharing does not necessarily slow the rate of growth. There is some evidence that spending growth is inversely related to the level of out of pocket payment, but the results are not definitive. This point is also related to the policy sensitivity to two class medicine, discussed earlier. The Rivlin-Domenici report holds out the hope that this step would lower private sector spending growth enough to keep it close to the necessary cuts in public sector spending growth, so that a gap between the two sectors would not emerge. Anything is possible, but at present there is not definitive evidence that changing the tax treatment will lower private spending growth over the long term to anything near the rates that would match the needed cuts in public spending growth.

\section{Policy options for containing government spending growth.}

I have already commented on the main fork in the road for public spending: either limit it and permit supplementation, or limit and cap overall spending by not permitting (or discouraging) supplementation. It is this latter (spending cap) model which leads to questions of how Medicaid and the public Medicare option might change how it reimburses providers and charges premiums and out of pocket payments to insureds. Assume then that there is to be only one plan that recipients of subsidized coverage can choose. It has to limit spending growth to a predetermined level. How might it best do so?

The most obvious point is that it should use a mix of strategies since moving on many margins is likely to do less harm than loading all the changes on any one item. On the provider side the most important thing to know is the answer to the provider problem posed earlier: when providers are told that they will only get a given (lower-than-otherwise) amount and told they are to do the best they can, what will they do? We need to know provider supply behavior. If Medicare, Medicaid, and the subsidized plans 
in exchanges combined and proposed to pay doctors and hospitals less, would they avoid these patients (we already know that happens with Medicaid), and to what extent? There will only be a shrunken private sector left, so not all physicians can shift to concierge medicine. And, as we saw, private insurers with no tax subsidy may choose to copy these cuts.

In theory, the answer depends on both the level of payment and the form it takes. Begin with the simplest case: Accountable Care Organizations have swept the field, signed up everyone and taken responsibility for their care, and are receiving de facto risk adjusted capitation payments. Compared to what otherwise would have happened, what would they cut? The simplest story is that they should cut whatever is the least cost effective. They might be assisted in doing so or in defending what they are doing by comparative effectiveness research evidence provided by the government's new program if there had previously been uncertainty or controversy about effectiveness. However, the relevant changes here would not be movement to more effective but less costly alternatives (which provides the policy case for this information) but rather movement toward slightly less effective but much less costly alternatives. They might also be assisted by the IPAB if it ordered, sanctioned, or justified the lower quality care-for example, by stipulating that using lower cost but better outcome hospitals at considerable distance represented higher quality care, even if the travel and inconvenience cost was greater than the value of improved health outcomes.

Things might predictably be different if the payment system is different-even if the final bill for the government remained the same. For example, suppose Medicare (and Medicaid) continued to pay hospitals per DRG and doctors per designated service, but sat on the annual update enough to achieve lower spending growth (offsetting any target income behavior by physicians by reducing fees still further). Doctors might just take fewer Medicare patients, increasing delays, travel time, and the like. Hospitals presumably would not decline patients but would reduce some dimensions of the quality of 
care per discharge that they render. But the outcome would not necessarily be worse than under capitation, since the low prices cap the alleged fee for service incentive to do more.

On the demand side, there are two broad strategies. The simplest, already discussed in the context of rising spending, is for the government simply to make less available as the implicit voucher for public coverage, so beneficiaries must either pay themselves for more coverage and more use or go without. The second is a more paternalistic and more targeted approach to "patient engagement," where things are designed not just to save money but channel, nudge, or require consumers/patients to do what policymakers think is best for them. (The political divide between these two approaches is obvious.)

\section{Means testing government health insurance.}

The most frequently discussed method of shifting both costs and the power to choose to consumers is to contemplate means testing of both premiums and benefits in public programs. Lower income people are usually left out, because it is assumed that they cannot as well afford to pay on their own (even though there is no definition and no test for "affordability."). What these lower income people get for free could be what is available in the market, or the government could directly control the services to this population-or some combination of control and market supply. When there are potentially strict limits on what the "non-means-tested" population gets, means testing is then not necessarily a totally bad thing for those who must pay. They do have to hand over their own money, but in return they get greater freedom to choose what they want.

There is a simple and compelling logic that says that tax-financed funding should not be used to subsidize health insurance or care for people with income or wealth high enough to pay entirely on their own. By extension, people who can pay some of the cost because their income is moderately high should do so. This "means-testing" or "income-conditioning" of subsidies obviously characterizes 
Medicaid: a person is eligible only when poor. It also characterizes the planned insurance programs for individuals and small businesses offered through exchanges, where subsidies are on a sliding scale-but go up to 400 percent of the poverty line. In the exchanges as well poor people only get very generous coverage at no cost, but those partially subsidized would have to pay extra for such coverage.

Means- testing does not now generally characterize Medicare: a low income senior can get subsidized coverage, but so can a billionaire. There is some modest adjustments for very high income people in terms of higher part B premiums, and for very low income people in terms of more generous Part D benefits - and the poorest seniors are also eligible for Medicaid which picks up much of what Medicare does not cover. But generally Medicare's subsidies flow to people because they are elderly, disabled, or have failed kidneys, not because they are poor.

This characteristic has made many policymakers, including President Obama, discuss the possibility of greater means testing in Medicare. Whether presented by Republican or Democrat, this change is suggested regretfully. If we could continue with today's Medicare "as we know it," we would, and few argue that means testing in itself is a good thing. Rather, it is viewed as a way of preserving much of Medicare, otherwise at serious risk, that is superior to other alternatives.

There are some soft and unresolved policy issues here. For one thing, although everyone talks about "affordability," no one knows what it means or exactly how much someone at some income level can "afford." Ultimately affordability is a subjective (and therefore inevitably controversial) political judgment (Bundorf and Pauly 2006). More seriously, when subsidies in a program fall as income rises, that constitutes a kind of tax on income, which can generate excess burden. So although the purpose of means testing is to reduce public spending and thus reduce the excess burden of taxation, if this is done via means testing offsetting excess burden is created elsewhere in the income distribution. The "net" tax on income (as income rises taxes go up and subsidies go down) is what matters. 
We can say something about extremes: a small program that cut spending by subsidizing only the very poor and then steeply phases out probably has low net excess burden since it distorts incentives (even though strongly) for only a small part of the population. And higher taxes paid out of current income arguably distort work effort decisions more than the prospect of lower Medicare benefits if the higher current income meant higher pensions after retirement. The idea is that I would worry when I am 30 that if earn more now and put it toward my pension income I would have to pay more taxes when I am 65. Finally, the strongest argument against means testing for Medicare (or Social Security) is that it would weaken middle class support for such programs if they are less beneficial to the middle class; if one takes as given that the program is a good thing, this is bad political economy. A less biased view of democracy would imagine that the middle class should not be manipulated into supporting social insurance but should be permitted to choose it-and the net lifetime subsidy it appears to transfer to lower income people-in a transparent way. Moreover, if Medicare will have to make the kinds of cuts in program quality across the board without means testing-if it will come to look more like Medicaidthose cuts may well erode middle class support much more effectively than under income-conditioning which preserves a substantial core level of tax financed support for insurance for seniors.

But the real question about means testing Medicare is whether it would be worth the political troublewhether it is a way to seriously lower the level or the growth rate of government spending on the program. The prospect for having seniors pay more for Medicare is a complicated question-first because of conflicting data, but fundamentally because it raises deep issues about consumer behavior and social values.

The more seniors there are who can "afford" to pay additionally for Medicare, the better. We do not know where the boundaries are on affordability but we are pretty sure it is higher the higher one's income, other things equal. Here we get mixed results. The fraction of seniors in households with 
incomes below the poverty line is smaller than for the rest of the population in the United States. But so is the fraction of people with incomes above $400 \%$ of the poverty line. Many elderly households make it into the lower middle class because Social Security benefits are enough to put them there-but they have little room to spare.

One of the "other things" that affect affordability is wealth. Here again we get conflicting evidence. Seniors at any income level have more wealth than other Americans. In part that is housing wealth; they have a fully paid up mortgage on their house. In part the wealth is their retirement fund that (especially at today's low interest rates) generates the moderate incomes they report. The conflict arises because neither of these items represents idle wealth-seniors want to live in their homes, and they want to live on their retirement funds. Of course, the presence of these two sources of wealth also means they are better off and can enjoy higher consumption than younger people with the same income: with no mortgage to pay and the ability to draw on my retirement fund, I can consume considerably more than the income I report to the IRS, or at least a much larger fraction compared to when I was young.

So what might be possible? Here are some calculations that give a rough idea. The first line in this table, taken from my earlier work (Pauly 2004, p. W4-553, exhibit 2), shows that with no means testing and spending growth limits, the proportional Medicare spending burden will be about $6 \%$. (Without growth limits it would be $10 \%$.) Taking that as a benchmark, the next two lines show the effect of limiting real spending growth by means testing higher income elderly populations. As can be seen, these steps reduce the burden on GDP down to a range of 4 to $5 \%$. The last line shows the effect of very aggressive means testing, boosting the proportion of the population subject to $60 \%$ of all seniors, actually provides little benefit. 


\begin{tabular}{lll}
\multicolumn{2}{l}{ Alternative Medicare Tax Rate Scenarios } \\
\hline $\begin{array}{l}\text { Percent of population means- } \\
\text { tested as "non-low-income" }\end{array}$ & $\begin{array}{l}\text { Real growth in Medicare spending } \\
\text { per non-means-tested beneficiary }\end{array}$ & $\begin{array}{l}2035 \text { tax rate as } \\
\text { percent of GDP }\end{array}$ \\
\hline & & $6.0^{2}$ \\
0 & GDP $+1 \%$ (approx. 2.8\%) & 4.6 \\
40 & GDP + 1\% & 3.9 \\
60 & GDP $+1 \%$ & \\
\hline
\end{tabular}

These illustrative calculations show that means testing will help, but for it to make a serious dent in spending growth it will have to be dramatic and it will have to be associated with something to slow the growth in spending. I discuss a way to do this further below.

Means testing, public spending growth, and the transition from work to retirement.

The implication of the previous discussion is that there is serious potential in means testing for Medicare but it will be tricky business. One reason why this is so is the same point discussed earlier: the real problem with Medicare is not the level of public funding but its rate of growth. Tapping wealthier seniors will help with the level, but not obviously with the rate of growth. However, I dealt with this problem in my earlier work by suggesting, in effect, that means testing be limited to payment for growth in excess of some baseline rate the public sector can afford. That would, by definition, impact the long run rate of growth in public spending.

There is a deeper problem. For reasons we do not well understand, household consumption levels tend to drop dramatically when people retire-even though economic models say that people should save, buy annuities, and establish pensions so that they can keep up their consumption after retirement. Basically a very large chunk of the upper middle class seems to disappear after retirement. Less

\footnotetext{
${ }^{2}$ Assumes that the GDP growth rate equals the "excess" Medicare population growth rate (Pauly 2004).
} 
precisely measured but probably true is that the rate of growth of income (broadly defined to include growth in the value of wealth like unrealized capital gains) also seems to slow dramatically after retirement. The original premise was that desired growth in medical spending is driven by or facilitated by growth in income. But if seniors' incomes do not grow much, maybe they would not be willing to pay much more for new technology. Medicare's financing means that presently we do not ask them to pay, but one might use what they would have valued as a benchmark for what society should buy-and what they value may be relatively modest growth.

This may be good logical news, because it means that slower growth even in total spending for seniorsthe kind of pattern that raises the specter of two-class medicine-may actually be efficient even without taking excess burden of the way we finance it into account.

\section{Some odds and ends: other solutions to the fiscal problem.}

Here I briefly comment on two other smaller policy changes intended to help Medicare's fiscal future: raising the age of eligibility and doing something about the cost-increasing effects of voluntary Medigap insurance.

The arguments for raising the age of Medicare eligibility for seniors are similar to those already made (and implemented into law) for Social Security: people are living much longer than when these programs were passed, so the promise (if there was one) to help people as they get older should be slid upwards in the age distribution to reflect a commitment for a given number of expected years at the end of life, not a commitment at a given fixed age.

Raising the age of eligibility does help with Social Security, because benefit payments (given the age at which the person retires) are fixed. If I am going to get $\$ 2000$ per month from Social Security when I 
retire, postponing the age at which I can collect that amount by two years saves the taxpayers $\$ 24000$ plus interest. Medicare is a little different. Average benefit costs are on the order of $\$ 10,000$ per beneficiary, but they start out lower at age 65 , rise until the person is in their mid-80s, and then decline as people eschew heroic measures as the probability of death rises. This means that raising the age will save something, but not as much (as a proportion of the total) as a similar step in Social Security. The other difference is that the need to pay for medical spending does not go away even if Medicare does; the alternative to insurance coverage is not zero spending. If people have to arrange insurance in other ways, they will find it to be expensive. And if their incomes are low to moderate and they are no longer working for a firm that offers benefits, they will qualify for subsidies under the exchanges in the ACA. For both of these reasons, the fiscal benefits from raising the age of eligibility, while still positive, are not as large as they might seem.

The other change for which there is a stronger argument in theory has to do with Medigap. The government run Medicare program has some fairly serious cost sharing provisions intended to constrain use and spending: a hefty deductible for inpatient care, and 20\% coinsurance without limit for Part B services, coupled with declining coverage for long hospital stays. Most seniors have reacted to these gaps in coverage by voluntarily purchasing private but federally regulated Medigap insurance. They pay the full cost of the premium that covers what the Medigap plans pay out (and fairly substantial administrative costs and profits too), but they get financial protection. The problem is that they also get a mitigation of the cost sharing incentives to be frugal in use of care paid for by the government plan. The evidence is strong (though not bullet-proof) that people with Medigap impose higher costs on the government plans than those without. Proposed solutions involve banning Medigap coverage of some of the cost sharing, or the better idea of taxing Medigap to collect the costs it imposes on Medicare. President Obama has recently proposed the latter. 
Both of these steps might help Medicare's costs, but their contribution is likely to be modest. The stronger argument for them is that they tidy up the design of the current system, targeting help better and reducing the poster child for inefficiency. This may help permit some parts of the current system to better play a role in a reformed arrangement.

\section{Putting the pieces together.}

What does this discussion imply for how we will or how we should deal with the serious effect of medical spending growth on the federal budget? We begin by noting that this is definitely not a false alarm. Still, it is not as if the sky will fall tomorrow, and the political problem then is that it is always easier to postpone dealing with falling skies until it starts to happen-but then it is probably too late to deal with it sensibly if at all. Economics, even political economy, has little to add to the oft-told tale of defective telescopic faculties in politics; it only tells us that we need Cassandras to keep making the point that something has to be done, and better sooner than later.

My ideal solution to the problem of rising spending would be one that focused on the problem of rising spending. Specifically, there would be two politically chosen levels of spending growth. One would represent the taxpayers' choice about the benchmark rate of spending growth (and therefore the rate of addition of beneficial but costly new technology) that would be made available to the poor and near poor who receive $100 \%$ subsidized insurance. For the rest of the population, current real levels of public spending per beneficiary would be sustained, but support for growth would be means tested. For the well-off, the only existing publicly funded program is Medicare, so they would be promised continuing support for Medicare with a voucher that is constant in real dollar terms. However, people at this income level would be required to pay in full for any growth in spending. They could either supplement the voucher or choose to use it for a plan whose cost is constrained to be equal to the voucher amount. 
For Medicare and subsidized plans in the exchanges (if they come to pass), the rate of growth in the value of the voucher or subsidy amount would be means tested. Probably the maximum addition would be enough to cover the increase in spending growth in the low income benchmark plan, although there might be some reason to match private spending for especially desirable new technologies.

In all cases, people could use their voucher for either a private plan or a public plan if one exists that meets the criteria-but public plans would then have to make management decisions about how much and what kind of new technology to add. While the choice of plan is bound to be complex, I think it could be simplified if different plans adopted and specified the cost effectiveness rule they would be using to cover new technology.

How would this work? Current views are that the social value of an additional year of high quality health is about $\$ 50,000$. Suppose that rule was actually chosen by the benchmark plan for the poor and low income; it would pay for new technologies that added "quality adjusted" life years for this cost or less, but it would not pay more than $\$ 50,000$ per quality-adjusted life year for other programs. (I hasten to add that I am using a $\$ 50,000$ threshold here only as an example; if taxpayers were willing to pay more they could increase the value.) Other plans, available to the non-poor with additional private payment, could set different cost effectiveness criteria-- $\$ 100,000, \$ 200,000$, and so forth. Of course, the plans willing to pay for more costly technology that adds to health would have premiums that beneficiaries would have to pay that would be rising more rapidly than those plans that chose a lower cutoff.

Of course, right now neither political discourse nor cost effectiveness methodology are sufficient to allow this kind of differentiated and free market in medical care spending growth, and nothing will ever be perfect. But I believe that it would be possible to work toward this kind of system especially in Medicare. I do not look forward to the need to implement this kind of system; I wish our national income growth could somehow be high enough to permit Medicare as we know it to be sustained, but 
that seems unlikely based both on past history of income growth and the logic that requires ever higher income growth or ever-higher marginal tax rates to keep up with ever higher health spending growth.

\section{Conclusions.}

Federally funded medical insurance programs cannot continue at current rates of funding and spending growth. Neither Medicare nor Medicaid as we currently know them can feasibly be retained in their current forms. Necessary reforms will always look inferior to current practice, but current practice cannot persist; the policy question is how to return to sustainable financing while doing as little harm as possible. Some cuts are inevitable in the future, but they need to be rational and graceful.

Rising medical care spending is not the work of an enemy, the consequence of sloth and inattention, or even fundamentally due to distorted incentives (though there are some distortions). It arises because we seek and have the means to improve the quantity and quality of our years of life. But the public sector has special problems in keeping up with this desire, and those problems inevitably mean it will have to rein in spending sooner and with more force than in the voluntary private sector.

There are some modest steps that we know can produce modest temporary improvements across the board, and there are some promising if unproven and unprecedented ideas that are worth trying. My own preference is to increase the options for citizens to use voluntary private spending to cushion (and rationalize) the inevitable limiting of public financing, with larger transfers to bring about some fairness in the process. We do need to face and discuss the structure of systems which will allow some to get more than others in the future, but with a decent, reasonable, and sustainable foundation for all. 


\section{References.}

Anderson, G.F., B.K. Frogner, and U.E. Reinhardt. 2007. Health spending in OECD countries in 2004: An update. Health Affairs 26(5): 1481-1489.

Anderson, G.F., U.E. Reinhardt, P. S. Hussey, and V. Petrosyan. 2003. It's the prices, Stupid: Why the United States is so different from other countries. Health Affairs 22(3): 89-105.

Baicker, K., and J.S. Skinner. 2011. Health care spending growth and the future of U.S. tax rates. NBER Working Paper 16772, February.

Boards of Trustees of the Federal Hospital Insurance and Federal Supplementary Medical Insurance Trust Funds. 2011. Annual Report. Washington, DC: Centers for Medicare and Medicaid Services. https://www.cms.gov/reportstrustfunds/downloads/tr2011.pdf (accessed November 11, 2011).

Boccuti, C., and M. Moon. 2003. Comparing Medicare and private insurance growth rates in spending across three decades. Health Affairs 22(2): 230-237.

Bundorf, M.K., and M.V. Pauly. 2006. Is health insurance affordable for the uninsured? Journal of Health Economics 25(4): 650-673.

Cutler, D.M. 2004. Your Money or Your Life: Strong Medicine for America's Health Care System. New York: Oxford University Press.

Finkelstein, A. 2003. Health policy and technological change: Evidence from the vaccine industry. NBER Working Paper 9460, January.

Fuchs, V.R. 2011. Who Shall Live? Health, Economics, and Social Choice. 2nd exp. ed. River Edge, NJ: World Scientific. 
Gawande, A., D. Berwick, E. Fisher, and M.B. McClellan. 2009. 10 steps to better health Care. The New York Times. New York ed., August 13, A27.

Grannemann, T.W., and M.V. 2010. Medicaid Everyone Can Count On: Public Choices for Equity and Efficiency. Washington, DC : AEI Press.

Krugman, P. 2011. The Conscience of a Liberal: Health Care Zombies. The New York Times, June 5. http://krugman.blogs.nytimes.com/2011/06/05/health-care-zombies/ (accessed November 11, 2011).

Laugesen, M.J., and S.A. Glied. 2011. Higher fees paid to US physicians drive higher spending for physician services compared to other countries. Health Affairs 30(9):1647-1656.

Naylor, M.D., D. Brooten, R. Campbell, B.S. Jacobsen, M.D. Mezey, M.V. Pauly, and J.S. Schwartz. 1999. Comprehensive discharge planning and home follow-up of hospitalized elders. Journal of the American Medical Association 218(7): 613-620.

Pauly, M.V. 2010. How stable are insurance subsidies in health reform? The Economists' Voice 7(5): Article 6. http://www.bepress.com/ev/vol7/iss5/art6 (accessed February 21, 2011).

Pauly, M.V. 2008.Markets Without Magic: How Competition Might Save Medicare. Washington, DC: AEI Press.

Pauly, M.V. 2004. Means-testing in Medicare. Health Affairs Web Exclusive, December 8, 2004. http://content.healthaffairs.org/cgi/reprint/hlthaff.w4.546v1 (accessed September 27, 2011).

Pauly, M.V. 2003.Should we be worried about high real medical spending growth in the United States? Health Affairs Web Exclusive, January 8, 2003. 
http://content.healthaffairs.org/content/early/2003/01/08/hlthaff.w3.15.citation (accessed September 27, 2011).

Pauly, M.V. 2011.The tradeoff between quality, quantity, and cost: How to make it if we must. Health Affairs 30(4): 574-580.

Pauly, M.V. 1993. U.S. health care costs: The untold true story. Health Affairs 12(3): 152-159.

Phelps, C.E. 2003. Health Economics. 3rd ed. Upper Saddle River, NJ: Prentice Hall.

Rivlin, A., P. V. Domenici, and the Bipartisan Policy Center's Debt Reduction Task Force. 2011. Restoring America's Future. Washington, DC: Bipartisan Policy Center. http://www.bipartisanpolicy.org/projects/debt-initiative/about (accessed October 17, 2011).

Skinner, J.S. 2011. Geographic variation in spending and outcomes. In Handbook of Health Economics, Vol. 2, ed. M.V. Pauly, T.G. McGuire, and P.P. Barros, chapter 2. Amsterdam: Elsevier (forthcoming). 